\title{
Hubungan Berat Lahir dengan Skor Gangguan Pemusatan Perhatian/ Hiperaktivitas pada Anak yang Memiliki Riwayat Berat Badan Lahir Rendah Kecil Masa Kehamilan
}

Priscilla C. Kalensang, Hesti Lestari, Johnny Rompis, Suryadi Tatura

Bagian/KSM Ilmu Kesehatan Anak Fakultas Kedokteran Universitas Sam Ratulangi/RSUP Prof. Dr.RD. Kandou, Manado

Latar belakang. Berat badan lahir rendah kecil masa kehamilan (BBLR KMK) masih merupakan penyebab utama masalah kesehatan pada anak, termasuk gangguan pemusatan perhatian/hiperaktivitas (GPPH). Hubungan yang konsisten antara BBLR KMK dan GPPH hingga kini masih diperdebatkan. Penanganan GPPH sedini mungkin dapat memperbaiki prognosis GPPH sehingga alat diagnosis yang baik menjadi penting. Abbreviated Conners Rating Scale (ACRS) merupakan alat yang mudah dan sudah divalidasi dalam mendeteksi GPPH.

Tujuan. Untuk melihat hubungan BBLR KMK dengan GPPH pada anak usia 5-8 tahun dengan menggunakan ACRS.

Metode. Desain penelitian adalah penelitian observasional dengan pendekatan potong lintang pada periode 1 November 2016 sampai 31 Januari 2017. Subyek penelitian adalah anak usia 5-8 tahun yang lahir di RSUP Prof Dr. R.D Kandou, Manado, dengan riwayat BBLR KMK. Besar subyek penelitian minimal 38 anak $(\alpha=0,05 \%, p=0,8)$. Variabel bebas adalah berat lahir dan variabel tergantung adalah skor ACRS. Analisis statistik menggunakan uji Pearson dan regresi linear. Statisik bermakna bila p $<0,05$.

Hasil. Pada penelitian ini didapatkan 40 anak yang memenuhi kriteria inklusi, 16 perempuan, dan 24 laki-laki. Rerata umur subyek penelitian adalah 6,8 tahun dan rerata berat lahir 2055 gram. Skor ACRS yang didapatkan antara 3-14 dengan rerata 8,4. Analisis bivariat didapatkan hubungan negatif sangat kuat dan sangat bermakna antara berat lahir dan skor GPPH $(r=0,883$ dan $p<0,0001)$, dengan uji regresi linear didapatkan persamaan $y=24,493-0,008 x$.

Kesimpulan. Semakin rendah berat lahir anak dengan riwayat BBLR KMK maka semakin tinggi kemungkinan terjadinya gangguan pemusatan perhatian dan hiperaktivitas (GPPH). Skor ACRS dapat digunakan sebagai skrining awal GPPH pada anak pra sekolah (5-8 tahun). Sari Pediatri 2019;21(3):170-6

Kata kunci: ACRS, ADHD, BBLR, kecil masa kehamilan

\section{Association between Birth Weight and Attention Deficit/Hyperactivity Disorder Score in Children with History of Low Birth Weight, Small for Gestational Age}

Priscilla C. Kalensang, Hesti Lestari, Johnny Rompis, Suryadi Tatura

Background. History of low birth weight, small for gestational age (LBW-SGA) is still a leading cause of child health problem, including attention deficit/hyperactivity disorder (ADHD). A consistent association between history of low birth weight, small for gestational age and ADHD is still controversial. Early treatment of ADHA could improve ADHD outcome; therefore, a good diagnostic tool is important. Abbreviated Conners Rating Scale (ACRS) is an easy, validated tool to detect ADHD.

Objective. To identify the association between low birth weight, small for gestational age with ADHD in children age 5-8 years old using ACRS.

Method. This study was a cross-sectional, observational study done on November $1^{\text {th }}, 2016$ until January, $31^{\text {th }}, 2017$. Study subjects were children aged 5-8 years old born at Prof Dr. R. D. Kandou General Hospital Manado with history of low birth weight, small for gestational age. Minimal sample size was 38 children $(\alpha=0.05 \%, p=0.8)$. Independent variable was birth weight and dependent variable was ACRS score. Statistical analysis was done with Pearson test and linear regression. P-value was considered statistically significant if $\mathrm{p}$ value $<0.05$.

Result. There were 40 children fulfilled the inclusion criteria, consist of 16 females and 24 males. The mean age of subjects was 6.8 years old and the mean birth weight was 2,055 grams. ACRS score was $3-14$ (mean 8,4). Bivariate analysis showed a strong negative association between birth weight and ADHD score $(r=0.883$ and $\mathrm{p}<0.0001)$, with linear regression test with linear regression test showing $y=24.493-0.008 x$.

Conclusion. Lower birth weight in children with history of LBW-SGA is associated with higher risk of ADHD. ACRS score can be used as early screening tool in preschool children (5-8 years old). Sari Pediatri 2019;21(3):170-6

Keywords: ACRS, ADHD, low birth weight, small for gestational age

Alamat korespondensi: Priscilla C. Kalensang. Bagian Ilmu Kesehatan Anak, RSUP Prof. R.D. Kandou, Jl. Raya Tanawangko No 56, Malalayang Satu Barat, Manado, Sulawesi Utara 95163. Email: priscillacantia@yahoo.co.id 
Priscilla C. Kalensang dkk: Hubungan berat lahir dengan Skor GPPH pada anak yang memiliki riwayat BBLR KMK

$\mathrm{D}$ ua pertiga bayi kecil merupakan berat bayi lahir rendah kecil masa kehamilan (BBLR KMK). Kecil masa kehamilan didefinisikan sebagai bayi dengan berat lebih rendah dari populasi normal atau lebih rendah dari perkiraan berat sesuai usia gestasinya. Berat badan lahir rendah didefinisikan sebagai bayi yang lahir dengan berat badan kurang dari 2500 gram. ${ }^{1}$ Berdasarkan hasil studi observasional berskala besar didapatkan hubungan antara gangguan kognitif dengan BBLR, panjang badan lahir yang pendek, dan lingkar kepala yang kecil untuk masa kehamilan. Bayi yang terlahir sebagai bayi KMK memiliki kemampuan kognitif yang rendah, terutama dalam bidang matematika dan pemahaman membaca, lebih emosional, dan memiliki gangguan pemusatan perhatian dan hiperaktivitas (GPPH). ${ }^{2}$ Namun demikian, hubungan yang konsisten antara BBLR KMK dan GPPH sampai saat ini masih diperdebatkan. ${ }^{3}$

Angka kejadian GPPH pada anak sangat bervarisi di antara beberapa negara. Angka kejadian GPPH berkisar antara 2\%-16\%, tergantung dari kriteria diagnostik dan alat ukur yang digunakan. ${ }^{4}$ Skala Conners adalah skala yang paling banyak digunakan untuk menilai perilaku anak GPPH. Skala ini sudah digunakan sejak tahun 1973 untuk menilai anak dengan gangguan hiperaktivitas dan telah divalidasi. ${ }^{5}$ Oleh karena itu, peneliti ingin meneliti hubungan berat badan lahir dengan gejala dari gangguan pemusatan perhatian dan hiperaktivitas $(\mathrm{GPPH})$ pada anak dengan riwayat BBLR KMK di Kota Manado menggunakan skor Abbreviated Conners Rating Scale (ACRS).

\section{Metode}

Desain penelitian ini adalah observasional analitik dengan pendekatan potong lintang untuk melihat hubungan berat lahir dan skor GPPH pada anak dengan riwayat BBLR KMK. Penelitian ini dilakukan di Kota Manado pada tanggal 1 November 2016 sampai dengan 31 Januari 2017. Kriteria inklusi adalah anak sehat usia 5-8 tahun yang dilahirkan dengan riwayat BBLR KMK di RSUP Prof. Dr. R.D Kandou Manado, memiliki status gizi baik, mempunyai rekam medik catatan berat lahir dan usia kehamilan, memiliki alamat yang jelas di Kota Manado, orang tua atau wali anak menyetujui dan menanda tangani formulir informed consent, serta mengisi kuesioner penelitian. Kriteria eksklusi adalah anak yang lahir dari ibu perokok dan peminum alkohol, anak yang memilki anggota keluarga terdiagnosis GPPH, anak dengan riwayat cedera kepala. Variabel tergantung adalah skor GPPH (ACRS) dan variabel bebas adalah berat lahir anak dengan riwayat BBLR KMK.

Analisis statistik yang digunakan adalah analisis deskriptif. Pertama, dilakukan analisis terhadap karakteristik variabel penelitian, yaitu berat badan waktu lahir dan skor GPPH yang ditampilkan berupa nilai rerata (mean), simpangan baku, nilai tengah (median), rentang minimum dan maksimum. Kedua, dilakukan analisis bivariat untuk mengetahui ada atau tidak hubungan antara berat lahir anak yang memiliki riwayat BBLR KMK dengan GPPH. Digunakan uji korelasi Pearson karena semua data berdistribusi normal atau parametrik. Semua data yang terdapat dalam formulir penelitian diolah dan dilakukan analisis statistik dengan menggunakan program komputer SPSS versi 22.

\section{Hasil}

Anak BBLR KMK yang lahir di RSUP Prof. Dr. R. D. Kandou Manado pada periode tahun 2008-2011 sejumlah 99 anak. Subyek penelitian berdasarkan data rekam medik yang dapat dihubungi dengan metode consecutive sampling sebanyak 40 anak (16 domisili di luar daratan Manado, 3 meninggal, 27 tidak dapat dihubungi, 11 orang tua menolak berpartisipasi, 2 subjek dieksklusi karena ibu merokok dan minum alkohol).. Karakteristik subyek penelitian adalah rentang umur 5,6-8,5 tahun, berat badan lahir 1350-2460 gram dan laki-laki lebih banyak daripada perempuan. Semua subyek penelitian memiliki status gizi baik. (Tabel 1). Hasil penilaian skor Abbriviated Conner Rating Scale (ACRS) subyek penilaian didapatkan rerata 8,4 (simpangan baku 2,8). Median scor ACRS adalah 8,0 (rentang 3-14). Skor ACRS dibagi berdasarkan berat badan lahir, yaitu BBLR (1500-2500 gram), BBLSR (1000-1500 gram) dan BBLASR (<1000 gram) (Tabel 2). Pada kategori BBLSR, semua skor di atas 13. Analisis univariat dilakukan terhadap beratbadan lahir anak dengan riwayat BBLR KMK (variabel bebas) dan skor ACRS anak tersebut (variabel tergantung). Didapatkan 
kedua variabel terdistribusi normal. Analisis bivariat hubungan antara berat badan lahir dan skor ACRS dengan uji Pearson didapatkan hubungan negatif kuat yang sangat bermakna $(r=-0,883 ; p<0,0001)$. Hasil ini menunjukkan bahwa semakin rendah berat badan lahir anak dengan riwayat BBLR KMK maka semakin tinggi skor GPPH (Gambar 2) Hasil uji regresi linear didapatkan persamaan:

$$
y=24,493-0,008 x, p<0,0001, R^{2}=0,778
$$

Tabel 1. Karakteristik subyek penelitian

\begin{tabular}{lc}
\hline Variabel & $\mathrm{N}=40$ \\
\hline Umur (tahun) & $6,8(0,7)$ \\
$\quad$ Rerata (SB) & $6,8(5,6-8,5)$ \\
Median (Rentang) & \\
Jenis kelamin (\%) & $16(40)$ \\
$\quad$ Perempuan & $24(60)$ \\
Laki-laki & \\
Berat badan lahir (gram) & $2055,8(311,9)$ \\
Rerata (SB) & 2050 \\
Median (Rentang) & $(1350-2460)$ \\
& \\
\hline
\end{tabular}

Tabel 2. Skor ACRS pada subyek pe nelitian yang dibagi berdasarkan berat badan lahir

\begin{tabular}{lcc}
\hline Berat badan lahir & Rentang skor & $\mathrm{N}(\%)$ \\
\hline $1500-2500$ & $3-<13$ & $35(92)$ \\
& $\geq 13$ & $3(8)$ \\
$1000-<1500$ & $3-<13$ & $0(0)$ \\
& $\geq 13$ & $2(100)$ \\
$<1000$ & - & - \\
\hline
\end{tabular}

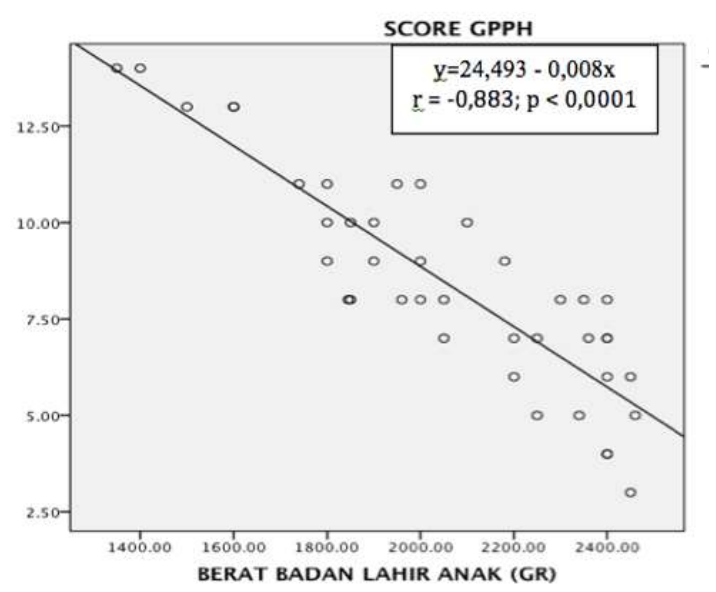

Gambar 1. Hubungan berat badan lahir anak dengan scor gangguan pemusatan perhatian dan hiperaktivitas.

\section{Pembahasan}

Diperkirakan sekitar 2\%-20\% anak usia sekolah di Amerika Serikat mengalami GPPH dan rasio anak lakilaki dan perempuan berkisar antara 3-5:1. ${ }^{6}$ Di kalangan usia remaja, angka kejadian GPPH menurun, baik pada perempuan maupun laki-laki, tetapi jumlah anak lakilaki tetap lebih banyak daripada perempuan dengan rasio perbandingan 3:1. Rasio ini bahkan lebih tinggi lagi dalam sampel klinis, perbandingannya mencapai 6:1 atau bahkan lebih. ${ }^{6}$ Golmirzaei $\mathrm{dkk}^{7}$ melaporkan bahwa GPPH didiagnosis tiga kali lebih banyak pada anak laki-laki dibandingkan perempuan. Penemuan ini juga konsisten dengan penelitian $\mathrm{Kim}_{\mathrm{dkk}}{ }^{8}$ dan Cantwell. ${ }^{9}$ Pada penelitian kami, di antara 24 subyek anak laki-laki, empat anak memiliki skor $\geq 13$.

Rerata usia subyek penelitian kami adalah 6,8 tahun. Hal ini konsisten dengan Golmirzaei $\mathrm{dkk}^{7}$ dalam studi case-control yang menggunakan pendekatan potong lintang. Golmirzaei dkkmelaporkan bahwa hampir semua gejala GPPH timbul setelah usia 3 tahun dan sebelum usia 7 tahun. Bahkan, gejala ini kemudian berlanjut sampai dewasa serta memengaruhi hubungan interpersonal, kemampuan akademik, serta masalah dalam keluarga dan pekerjaan. Mayoritas subyek yang mengalami gangguan ini mulai membutuhkan bantuan pada usia 6-9 tahun, walaupun banyak orangtua yang menginformasikan bahwa masalah telah muncul sejak anak duduk di Taman Kanak-kanak. ${ }^{6}$ The Federal Drug Administration tidak pernah merevisi rekomendasi pemberian metilfenidat, yaitu mulai dari usia 6 tahun atau lebih. Oleh karena itu, banyak studi yang menggunakan batasan 6 tahun untuk memulai pemberian terapi metilfenidat pada anak. ${ }^{10}$

Komponen terpenting untuk membuat evaluasi komprehensif terhadap anak yang mengalami GPPH meliputi wawancara klinis, penilaian perilaku berdasarkan skala penilaian perilaku secara lengkap, dan pemeriksaan medis. Skala penilaian perilaku GPPH pada umumnya merupakan instrumen narrow scale. Instrumen ini hanya memuat butir-butir ciri perilaku spesifik yang sesuai dengan karakterikstik psikopatologi GPPH sehingga dapat dipakai untuk membedakan dari gangguan atau disfungsi perilaku yang lain. ${ }^{11}$ Skala yang paling sederhana dan mudah dilakukan adalah abbreviated conners rating scale (ACRS). Skala ini terdiri dari 10 pertanyaan yang dapat ditanyakan kepada orang tua atau guru. Nilai cut off yang digunakan di Indonesia sebagai kemungkinan 
GPPH adalah total skor 13, sesuai buku KPSP. Berbeda dengan cut off yang digunakan di Indonesia, berbagai publikasi menggunakan total skor 15 sebagai cut off seperti yang telah divalidasi di brazil oleh Gilberto $\mathrm{dkk}^{12}$ pada tahun 1987. Kami mendapatkan skor ACRS dengan rentang 3-14. Berdasarkan nilai cut off buku KPSP maka kami mendapatkan empat orang anak tersangka GPPH yang memerlukan tindak lanjut.

Anak dengan tersangka GPPH terbanyak pada kelompok BBLSR dibandingkan dengan BBLR. $\mathrm{Hal}$ ini konsisten dengan penelitian meta-analisis sebelumnya yang menyimpulkan bahwa bayi dengan BBLSR memiliki defisit pada pencapaian akademik, masalah atensi, masalah perilaku dan kurangnya fungsi eksekutif yang berhubungan dengan maturitas pada saat lahir. ${ }^{13}$

Penelitian kami mendapatkan hasil skor Conners pada kelompok berat badan 1000-<1500 gram lebih tinggi dari kelompok berat badan lahir 1000-<1500 gram. Hal ini konsisten dengan penelitian sebelumnya. Hack dkk, ${ }^{14}$ menemukan anak dengan $\mathrm{BBL}<1500$ gram paling risikoberisikoberisiko terhadap munculnya masalah perkembangan, seperti palsi serebral, kebutaan, tuli dan intelegensi yang tidak normal. Mick $\mathrm{dkk},{ }^{3}$ mendapatkan bahwa anak dengan berat badan lahir amat sangat rendah tiga kali lebih risikoberisiko terjadi GPPH dengan gangguan perhatian. Scotish Low Birth Weight Study Group mendapatkan 47\% anak dengan berat lahir sangat rendah memiliki rentang atensi yang rendah dan peningkatan terjadinya gangguan perilaku. Botting dkk ${ }^{15}$ mendapatkan 23\% predominasi GPPH terjadi pada anak dengan berat badan lahir sangat rendah, .

Pada penelitian ini didapatkan hubungan negatif kuat yang sangat bermakna antara BBLR KMK. Semakin rendah berat badan lahir anak dengan riwayat BBLR KMK maka semakin tinggi skor ACRS. Skor ACRS ini digunakan untuk menskrining anak dengan GPPH. Hubungan BBLR dengan GPPH ini konsisten dengan penelitian sebelumnya. Sasaluxnanon $\mathrm{dkk}^{16}$ menggunakan DSM-IV TR dan $T$ score of Conners Teaching Rating scale untuk menilai GPPH dan melaporkan berat badan lahir kurang dari $2500 \mathrm{gr}$ mempunyai hubungan bermakna secara statistik dengan GPPH. Subyek yang menderita GPPH tersebut mempunyai berat badan lahir antara 1600-2400 gram. Indredavik $\mathrm{dkk},{ }^{17}$ mendapatkan hubungan bermakna antara anak dengan riwayat BBLR dan GPPH. Berbeda dengan penelitian ini, Indredavik $\mathrm{dkk},{ }^{17}$ menemukan tidak ada hubungan bermakna antara anak dengan riwayat KMK dan GPPH, meskipun jumlah skor pada anak dengan riwayat KMK lebih tinggi dibandingkan anak kontrol. Penentuan anak dengan GPPH pada penelitian tersebut menggunakan DSM IV-TR. ${ }^{18}$ Penelitian yang kontras dengan hasil penelitian ini dilaporkan di Kanada (2014). Lahat dkk $^{19}$ mendapatkan tidak ada perbedaan yang bermakna pada skor total GPPH antara BBLR dan BBL normal dengan menggunakan metode $A D H D$ rating scale (Barkley and Murphy, 1998). Walaupun demikian, bila menggunakan metode young adult self report (YASR) ternyata terdapat dugaan hubungan bermakna antara berat badan lahir dengan GPPH.

Hatch $\mathrm{dkk}^{14}$ melaporkan bahwa berat badan lahir dan usia gestasi berperan sebagai prediktor yang sama terhadap terjadinya GPPH. Usia gestasi memiliki validasi prediktor lebih tinggi dibanding berat badan lahir. Berat lahir memiliki efek yang tidak langsung melalui fungsi neuropsikologi primer. Metode yang digunakan untuk diagnosis GPPH adalah Conner Parent Rating Scale dan DSM IV-TR. ${ }^{20}$ Penelitian tersebut mendukung hasil penelitian ini. Hal ini konsisten dengan hasil penelitian meta-analisis sebelumnya yang mendapatkan bahwa mayoritas penelitian melaporkan adanya hubungan antara BBLR dengan GPPH.

Pada penelitian kami, subyek penelitian adalah subyek dengan BBLR KMK yang menyebabkan GPPH. Hubungan BBLR KMK dengan GPPH dapat dijelaskan secara umum dengan adanya restriksi pertumbuhan janin yang disebabkan asupan energi yang berkurang terhadap pertumbuhan organ. Restriksi pertumbuhan ini menyebabkan sub-optimal luaran perkembangan saraf di kemudian hari. ${ }^{17}$ Berat lahir rendah mengurangi volume grey matter dan white matter, menyebabkan gangguan fungsi koordinasi terhadap atensi, disfungsi eksekutif, dan fungsi kognitif. ${ }^{17}$ Dismaturitas juga berhubungan dengan biological programing atau peningkatan kerentanan terhadap kematian sel neuron. Kekurangan sel neuron, baik karena asupan energi yang berkurang selama kehamilan maupun kerentanan kematian neuron yang berhubungan dengan biological programing, akan menghasilkan sekuele neurologi dan gangguan perkembangan kortikal dan koneksitas di otak. ${ }^{21}$ Gangguan neurologi ini akan menyebabkan gangguan penurunan atensi dan peningkatan hiperaktivitas yang bermuara pada peningkatan gejala GPPH itu sendiri. 
Sinergitas kedua potensi, yaitu BBLR dan KMK akan menyebabkan GPPH. Hal tersebut tergambar dari hasil penelitian kami, yaitu adanya hubungan negatif kuat sangat bermakna antara BBLR dan KMK dengan skor ACRS. Namun demikian, kami mendapatkan bahwa tidak selamanya penurunan berat badan lahir pada anak dengan riwayat BBLR dan KMK ini secara konsisten berbanding lurus dengan skor ACRS yang merupakan gambaran terhadap potensi atau telah terjadinya GPPH.

Berdasarkan persamaan regresi linear didapatkan titik subyek penelitian berada di atas atau di bawah garis lurus. Terdapat subyek dengan berat badan sama memiliki skor GPPH yang berbeda atau bahkan subyek dengan berat badan lahir lebih rendah, tetapi memiliki skor ACRS yang lebih rendah pula. Hasil seperti ini dimungkinkan karena ada faktor lain yang berpengaruh dan tidak dapat dikontrol atau dieksklusi dalam penelitian kami.

Gangguan pemusatan perhatian dan hiperaktivitas (GPPH) dapat disebabkan beberapa faktor, yaitu genetik, risiko prenatal dan perinatal, psikososial, bahan-bahan racun dari lingkungan dan makanan. Faktor prenatal dan prerinatal, yaitu ibu yang merokok, peminum alkohol dan substansi yang terkandung di dalamnya serta stres maternal. Faktor-faktor risikorisiko genetic, yaitu gen dopamonergik (DRD4, DRD5), gen serotonergik (5HTT, HTR1B) dan gen SNAP-25. Bukti penelitian menyatakan bahwa faktor genetik merupakan faktor penting dalam memunculkan tingkah laku GPPH. Satu pertiga dari anggota keluarga GPPH memiliki gangguan, yaitu jika orangtua mengalami GPPH maka anaknya risikoberisiko GPPH sebesar 60\%. Pada anak kembar, jika salah satu mengalami GPPH, maka saudaranya 70\%-80\% juga risikoberisiko mengalami GPPH. ${ }^{6}$ Faktor genetik secara umum disingkirkan dengan mengeksklusi orang tua dengan riwayat GPPH ataupun apabila anak memiliki fasies dismorfik. Faktor bahan racun dari lingkungan, yaitu organofosfat, polikronated, seng, magnesium. Bahan-bahan kimia tersebut bekerja dengan mengganggu kerja dari neurotransmitter. Faktor psikososial, yaitu keberagaman keluarga dan pendapatan yang rendah, konflik orang tua dan anak, pemisahan anak dengan orang tua. Telah banyak studi yang menemukan bahwa faktor lingkungan bisa menjadi penyebab terjadinya GPPH pada anak. Sebagai contoh, penelitian sebelumnya secara konsisten mendapatkan bahwa pola asuh yang salah dari orang tua, dan kemiskinan merupakan faktor risikorisiko penyebab terjadinya GPPH, terutama pada mereka yang memiliki faktor genetik GPPH. ${ }^{13}$ Beberapa faktor perancu sudah dikeluarkan dengan kriteria eksklusi pada penelitian kami, yaitu ibu perokok dan peminum alkohol. Banyak penelitian yang menyatakan bahwa paparan terhadap alkohol selama kehamilan dapat meningkatkan risikorisiko gangguan perkembangan saraf dan konduktif. Ibu yang merokok selama hamil dilaporkan merupakan faktor risiko hiperaktivitas pada kebanyakan kasus. Obel $\mathrm{dkk}^{22}$ melaporkan $22 \%$ anak dengan ADHD memiliki riwayat terpapar asap rokok. Faktor prenatal yang berhubungan dengan pola hidup ibu selama kehamilan, seperti kebiasaan minum alkohol dapat berpengaruh terhadap struktur serebelum. Anak yang telah terpapar alkohol saat masih berada dalam uterus dapat menjadi hiperaktif, disruptif, impulsif. Merokok selama kehamilan dapat meningkatkan risiko terjadinya GPPH sebesar 2,7 kali lipat. Jumlah rokok yang dapat memengaruhi kejadian GPPH telah diteliti oleh Langley dkk. ${ }^{23}$ Berdasarkan studi Langley dilaporkan bahwa ibu hamil yang mengonsumsi rokok lebih dari 10 batang per hari dapat meningkatkan gejala hiperaktivitas dan impulsivitas. Hal ini disebabkan oleh efek terhadap reseptor nikotin yang memengaruhi sistem dopaminergik. Merokok dapat mengganggu fungsi normal dari plasenta dengan menurunkan aliran darah ke uterus. Penurunan pasokan oksigen dan nutrisi kepada janin menyebabkan hipoksia dan iskemik dan malnutrisi sehingga perkembangan janin terhambat. Faktor perancu lain yang dieksklusi adalah anak dengan riwayat trauma kepala. Dalam beberapa penelitian, anak dengan riwayat trauma kepala berisiko lebih tinggi untuk menjadi GPPH dibandingkan kontrol. Hasil ini konsisten dengan studi yang dibuat oleh Schachar $\mathrm{dkk}^{24}$ yang melaporkan bahwa GPPH lebih sering terjadi pada anak dengan riwayat trauma kepala sedang dan berat. Penelitian ini dilakukan pada anak-anak yang tinggal di Kota Manado, sehingga diharapkan dapat meminimalkan faktor lingkungan yang dapat memengaruhi hasil skor GPPH.

Kekuatan penelitian ini adalah pertama pada penggunakan skor ACRS. Skor ACRS ini lebih mudah dilakukan dan merupakan skrining awal di dalam menegakkan diagnosis GPPH dimana dapat mendeteksi lebih awal adanya kecenderungan terjadinya GPPH dan dapat mengetahui kapan memerlukan pemeriksaan yang lebih teliti serta penanganan yang cepat dan adekuat. Kedua, semua 
subyek penelitian merupakan BBLR KMK dimana belum pernah ada pada penelitian sebelumnya.

Keterbatasan penelitian ini adalah pada desain penelitian yang sederhana dan tidak memasukkan semua variabel perancu yang mungkin memengaruhi terjadinya GPPH sehingga tidak dapat menganalisis seberapa besar pengaruh dari variabel bebas BBLR kecil masa kehamilan (KMK) dalam menyebabkan GPPH itu sendiri yang dapat ditampilkan dalam bentuk rasio odd atau faktor risiko, karena itu perlu penelitian dengan desain yang lebih kompleks dengan melibatkan semua faktor perancu sehingga dapat dianalisis seberapa besar pengaruh berat badan anak dengan riwayat BBLR KMK terhadap terjadinya GPPH.

Kesimpulan pada penelitian ini adalah terdapat hubungan negatif kuat yang sangat bermakna antara berat lahir anak yang memiliki riwayat BBLR (BBLR) kecil masa kehamilan (KMK) dengan skor Abbreviated Conners Rating Scale (ACRS) dimana semakin rendah berat badan lahir anak dengan riwayat BBLR KMK maka semakin tinggi kemungkinan terjadinya gangguan pemusatan perhatian dan hiperaktivitas (GPPH) pada anak. Perlu dilakukan pemeriksaan Abbreviated Conners Rating Scale (ACRS) pada anak usia pra sekolah ( $<5$ tahun) dengan riwayat BBLR KMK untuk mendeteksi terjadinya GPPH sedini mungkin sehingga dapat dilakukan penanganan secara dini dan adekuat.

\section{Daftar pustaka}

1. Gomela TL, Cunningham DM, Eyal FG, Tuttle DJ. Neonatology, management, procedures, on-call problems, diseases, and drugs. Edisi ke-7. New York: Mc Graw Hill education; 2013: h.29-42.

2. Bhutta AT, Cleves MA, Casey PH, Cradock MM, Anand KJS. Cognitive and behavioral outcomes of school-aged children who were born preterm, A meta-analysis. JAMA 2002; 288:728-37.

3. Mick E, Biederman J, Prince J, Fischer MJ, Faraone SV. Impact of low birth weight on attention-deficit hyperactivity disorder. J Dev Behav Pediatr 2002;23:16-22.

4. Cormier E. Attention deficit hyperactivity disorder. A review and update. J Pediatr Nurs 2008 23:345-57.

5. Lahey B, Pelham W, Atkins A, Loney J, Lee S. Instability of the DSM-IV Subtypes of ADHD from preschool through Elementary School. Arch Gen Psychiatry 2005;62:896-902.
6. Baihaqi MIF, Sugiarmin M. Memahami dan membantu anak ADHD. Bandung: Refika Aditama; 2006.

7. Golmirzaei J, Namazi S, Amiri S, Zare S, Rastikerdar N, Hesam A, dkk . Evaluation of attention-deficit hyperactivity disorder risk factors. Int JPediatr 2013;23:1-6.

8. Kim HW. Cho SC, Kim BN, Shin MS, Kim Y. Perinatal and familial risk factors are associated with full syndrome and subthreshold attention-deficit hyperactivity disorder in a Korean community sample. Psychiatry Investigation 2009;6:278-85.

9. Cantwell DP. Attention deficit disorder: a rewiew of the past 10 years. J Am AcadChild Adolesc Psychiatry 1996;35:978-87.

10. Wolraich ML. Attention-deficit/hiperactivity disorder: can it be recognized and treated in children younger than 5 years? Infant and young children 2006;19:86-93.

11. Ojeda NB, Grigore D, Alexandra BT. Intrauterine Growth Restriction: fetal programming of hypertension and kidney disease. Advanc in Chronic Kidney Dis 2008;15:101-6.

12. Gilberto B. The conners abbreviated teacher rating scale: development on Norms in Brazil. J Abnorm Child Psycol1987;15:511-8.

13. Petterson E, Sjolander A, Almqvist C, Anckarsater H, D'Onofrio BM, Lichtensen P, dkk. Birth weight as an independent predictor of ADHD symptoms: a within-twin pair analysis. J Child Psychol Psychiatry 2015;56:453-9.

14. Hack M, Taylor HG, Schulchter M, Andreias L, Drotar D, Klein N. Behavioral oucomes of extremely low birth weight children at age 8 years. J Dev Behav Paediatr 2009;30:122-30.

15. Botting N, Powls A, Cooke RWI, Maslow N. Attention deficit hyperactivity disorder and other psychiatric outcomes in very low birthweight children at 12 years. J Child Psychol Psychiatry 1997;38:931-41.

16. Sasaluxnanon C, Kaewpornsawan. Risk factor of birth weight below 2,500 grams and attention deficit hyperactivity disorder in Thai Children. J Med Assoc Thai 2005;88:1514-18.

17. Indredavik MS, Vik T, Evensen KA, Skranes J, Taraldsen G, Brubakk AM. Perinatal risk and psychiatric outcomes in adolescent born preterm with very low birth weight or term small for gestational age. J Dev Behav Paediatr 2009;31:28694.

18. Ahmed M, Verma S, Kumar A, Siddiqui M. Enviromental exposure to lead and its correlation with biochemical indices in children. Sci Total Environ 2009; 346: 48-55.

19. Lahat A, van Lieshout RJ, Saigal S, Boyle MH, Schmidt L. ADHD among young adults born et extremely low birth weight: the role of fluid intelligence in childhood. Frontier in Psycology 2014;5:1-7.

20. Menkes JH. Toxic and nutrional disorders. Dalam: Lippincott Wiliams and Wilkins; 2000.h.743-8 
21. Galera C, Cote SM, Bouvard MP, Pingault JB, Melchior M, Michel G, dkk. Early risk factors for hyperactivity-impulsivity and inattention trajectories from age 17 months to 8 years. Arch Gen Psychiatrty 2011;68:1267-75

22. Obel C. Linnet KM, Hendriksen TB. Smoking during pregnancy and hyperactivity-inattention in the offspringcomparing results from three Nordic cohorts. Int J Epidemiol 2009;38:698-705.
23. Langley K, Holmas P, Van M, Thapar A. Effects of low birthweight, maternal smoking in pregnancy and sosial class on the phenotypic manifestation of attention deficit hyperactivity disorder and associated antisosial behavior: Investigation in a clinical sample. BMC Pshyciatry 2007;27:26-34.

24. Schachar RJ, Park LS, Dennis M. Mental Health Implications of Traumatic Brain Injury (TBI) in Children and Youth. J Can Acad Adolesc Psychiatry 2015;24;2:100-108. 